\title{
Development of Universe
}

\author{
Dalvinder Singh Grewal* \\ Department of English, India \\ *Corresponding author: Dalvinder Singh Grewal, Department of English, Ludhiana, India6;
}

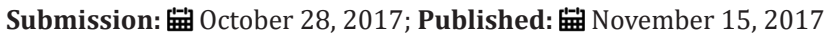

\section{Opinion}

The press was full with the news of discovery of Higgs Boson recently. Higgs Boson is stated to be the reason of mass and height of object according to Standard Theory of which it is this particle is the key element. Standard theory was created to prove that the universe was created through a Big Bang and the creation was through the particles as laid down in the Standard Theory. The theory of Big Bang was based on the assumptions that the universe was created with a bang. As per analogy, the bang could throw away the muck around and the particles spread all over haphazardly. The constellations, stars, planets and satellites thus would have been the result of haphazard development. However showing this development with the help of Standard Model appears anomalous. If the creation was haphazard, logically all the development has to be haphazard. It cannot be smooth and in a standard pattern. How can then the Standard Model apply to the development of universe in the absence of systems? How could the systems like rotations of planets around stars in pattern; day and night system etc., come into existence? Haphazard growth and existence of natural systems thus cannot go together. Standard Model can only apply if there is a set pattern and the origin is logical and systematic. Thus Big Bang Theory and Standard Model Theory do not stand together.

Answer to this puzzle is available in the supreme Sikh scripture Sri Guru Granth Sahib (SGGS). It explains: Sasai sabh jag sahj(i) upaia (SGGS:730:3) Hukmee sahje srist(i) upaaee (SGGS:1043:18). The entire universe was created smoothly and not through a bang. It was a systematic origin from the very beginning. He created the universe with one Word command. Ek kvavai te sabh(i) hoa (SGGS:1003:18) Eko kavao keeta pasao (SGGS p. 463, 929-30, 106) From this sound came out the energy the fundamental force of the universal existence. The waves originated from light and sound energy spread systematically and spread initially in the form of waves and formed into various elements from the light particles. Pasrio aap(i) hoi ant trang (SGGS: 275:8). Jot saroopee tat anoop (SGGS 344:1).

The creation was initially in the form of waves which later turned into particles. It however retained the property of duality i.e., both wave and particle forms. In fact from the wave all the particles were made and from these particles; the entire creation came into existence. According to Wave-Particle Duality Theory all particles are both particle and wave. The theory states that objects (light, electrons, bowling balls, ...) can at times appear to us as waves, and at other times as particles. In this sense they are neither particles nor waves, in an absolute sense, but only exhibit wave or particle properties, depending on the experiment being performed. Wave-particle duality lays down that all particles exhibit both wave and particle properties. As per Copenhagen interpretation, waveparticle duality is one aspect of the concept of complementarities that a phenomenon can be viewed one way or other, but not both simultaneously. Afshar's experiment (2007) has demonstrated that it is possible to simultaneously observe both wave and particle properties of photons (Figure 1).



Figure 1: Wave particle duality Model for photons.

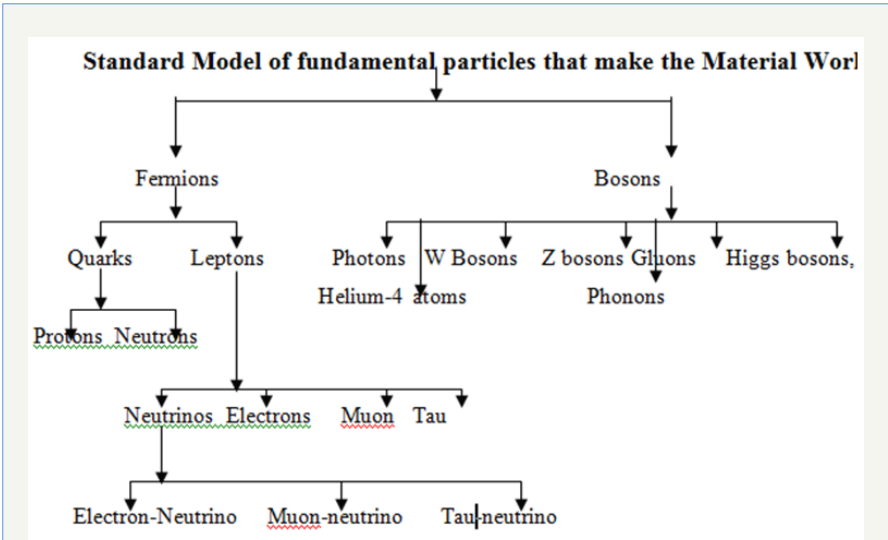

Figure 2: Standard Model of fundamental particles that make the Material World. 
SGGS has following to explain further: Jab dekhao tab sab kichhu mool. Nanak so sookham soee asthool. (SGGS: 281:17). The concept of nirgun and sargun (Sargun Nirgun Nirankar) in SGGS is also built on this since God's nature and His creation's nature is declared as the same: Us te bhin kah-hu kichh hoi. Than thanantar(i) eko soi. (SGGS: 279:8).The light remained in all the creation in continuity, unity in entirety. Jot(i) nirantar(i) janneai (SGGS 55:6). The standard Model can be easily applied to this theory of smooth origin and development model (Figure 2).

The Standard theories reveal that all particles are fundamentally in the wave form. This thus confirms that the solids, liquids and gases are fundamentally waves. This also further confirms that all waves are energies and in turn all solids, liquids and gases are various forms of energies which continuously change forms from one form to another and are never stable. The scientist community has reached up to various divisions of atoms, protons, neutrons \& electrons as quarks, leptons and bosons and up to neutrinos. The fundamental energy behind all these remains the One and the One alone and the divisions into various forces have also been narrowed down to one common force. Hence the science has moved fast to the unity of entire universe in the form of energy, though it is still grappling with the lowest part of the universe as it is grappling with the largest of the universe. We can thus conclude that divisions of the universe into various elements, is arbitrary and changing according to the knowledge at any particular time. There is no end to knowledge as there is no end knowledge of the Creator and His universal truths. This way the development process became systematic. Since the universe has many forms, colours and creeds it is stated to be created in many ways:

Nanak rachna prabh rachee bahu bidh(i) anik parekar. (SGGS:276:12), Kaee jugt(i) keeno bisthaar (SGGS 276:12), Rangi rangi bhanti kar(i) kar(i) jinsee maya jin upaee (SGGS 6:14)

God started the creation of various atmosphere and stratosphere above and netherlands below. The earth was created in between.
Once He created light, nights, seasons, lunar-days, week-days, wind, water, fire and nether lands and founded the continents and solar systems He established earth as a home for meditation. This way from the absolute self He became manifest in the universe. Having created the air, the Lord supported the whole earth and bound fire and water into a system: Paun upai dharee sabh dhartee jal agnee ka bandh(u) kia.(SGGS: P.350). Therein he placed the bodily forms of numerous types of colours and creeds: pawan pani agnee pataal. Tis(i) vich(i) thap(i) rakhee dharamsal. Tis(u) viich(i) jia jugt(i) ke rang. Tin ken am anek anant. (SGGS:7) Rangee range bhatee kar(i) kar(i) jinsee maya jin upai (SGGS:6). The Lord created and set the universe Ape qudrat kare saaj(i) (SGGS:1070). The Lord Himself is the Creator-Master of the body of five elements] Panch bhoo ko naiko aap(i) siranda jin(i) sach ka pind(u) swaria. (SGGS:766). The man originated from Lord's command: Hukmai awe hukme jawe hukme rahia samaee.(SGGS:940). He kept the entire universe bound into a single unit. Sagl smagree apne soot(i) dhari. (SGGS:276:1) according to Unified Theory. Every part of the universe is under His direct control. No one can go against His order [1]:

a. Aagiakari dhari sabh(i) sristee ( SGGS:281:19)

b. Hukm(i) andar(i) sabh ko bahr hukm na koi (SGGS: 1:9)

The change is the nature of the entire universe. Jo deesai so chalanhar (SGGS:268:13). Sabh jag chalanhar (SGGS: 468:7). Movement is circular; everyone joins wherefrom it originated: Jis te upje tis mah(i) samaee. (SGGS: 282:7). Prabh te hoi prabh me samai (SGGS: 276:13). The universe will ultimately merge in Him again. This universe was created and assimilated many time before also. Kai bar pasrio pasar (SGGS: 276:13). Final end or assimilation too is going to be smooth: Jio jal mah(i) jal ai khatana. Tio joti sanf jot smana. (SGGS 278:4). Thus the theory of Big Bang does not logically stand to test: the Smooth Origin and Standard Model go together.

\section{References}

1. Afshar SS (2007) Paradox in Wave Particle Duality. Found Phys 37(295). 